\title{
Heterogeneous Catalysis to Drive the Waste-to-Pharma Concept: From Furanics to Active Pharmaceutical Ingredients
}

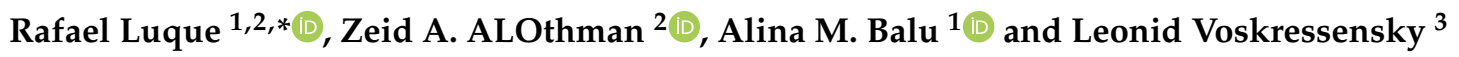 \\ 1 Departamento de Química Orgánica, Campus de Rabanales, Universidad de Córdoba, \\ Edificio Marie Curie (C-3), Ctra Nnal IV-A, Km 396, 14014 Cordoba, Spain; qo2balua@uco.es \\ 2 Chemistry Department, College of Science, King Saud University, P.O. Box 2455, Riyadh 11451, Saudi Arabia; \\ zaothman@ksu.edu.sa \\ 3 Department of Chemistry, Peoples Friendship University of Russia (RUDN University), \\ 6 Miklukho Maklaya St., 117198 Moscow, Russia; lvoskressensky@yandex.ru \\ * Correspondence: rafael.luque@uco.es or q62alsor@uco.es
}

check for

updates

Citation: Luque, R.; ALOthman, Z.A.; Balu, A.M.; Voskressensky, L. Heterogeneous Catalysis to Drive the Waste-to-Pharma Concept: From Furanics to Active Pharmaceutical Ingredients. Molecules 2021, 26, 6738. https://doi.org/10.3390/

molecules 26216738

Academic Editor: Farid Chemat

Received: 30 September 2021

Accepted: 2 November 2021

Published: 8 November 2021

Publisher's Note: MDPI stays neutral with regard to jurisdictional claims in published maps and institutional affiliations.

Copyright: (c) 2021 by the authors. Licensee MDPI, Basel, Switzerland. This article is an open access article distributed under the terms and conditions of the Creative Commons Attribution (CC BY) license (https:/ / creativecommons.org/licenses/by/ $4.0 /)$.

\begin{abstract}
A perspective on the use of heterogeneous catalysis to drive the waste-to-pharma concept is provided in this contribution based on the conversion of furanics to active pharmaceutical ingredients (APIs). The provided overview of the concept in this perspective article has been exemplified for two key molecule examples: Ancarolol and Furosemide.
\end{abstract}

Keywords: heterogeneous catalysis; waste-to-pharma; furanics; APIs

Society faces a daunting future in terms of water, food and resource scarcity. This has been evidenced by recent studies showing a significant diminishing of fossil fuel resources, the increasing generation of waste, as well as the expected increase in population in future years. Facing these challenges is not an easy task. A multidisciplinary team effort from many disciplines is needed to develop suitable alternatives for a more sustainable society able to deal with these important issues.

Waste is currently one of these alarming problems the planet is experiencing and will face in future years. In Europe, waste generation was reported to be over 2.25 billion tons in Western European Countries between 1998 and 2001 as well as 550 million in Eastern Europe Candidate Countries [1]. Main sources of such waste were construction (31\%), mining and quarrying (15\%) and most importantly, agricultural and forestry waste, which accounted for roughly $30 \%$ of the total generated waste. Agricultural and forestry waste residues currently find somewhat limited uses and exploitation different than burning, field rotting and/or composting, being under-considered despite their huge potential to be valorised.

Lignocellulosic residues (typically from tree debranching and cutting, left-overs from crops, municipal residues from packaging, etc.) comprise three markedly different fractions: hemicelluloses (30\%), cellulose (45\%), and lignin (25\%) [2], which can potentially be isolated separately (more difficult for hemicelluloses and cellulose) and processed to valuable products.

Derived from C5-C6 fractions, furanic compounds have recently attracted significant techno-economic considerations due to their production capabilities from non-edible parts of lignocellulosic biomass to produce fuels, chemicals and materials [3]. For this reason, some have been listed by the U.S Department of Energy as one of the top 12 and top 30 potential chemical building blocks [4]. In particular, Avantium's YXY ${ }^{\circledR}$ process produces furandicarboxylic acid (FDCA) for the development of the new generation of bio-plastics PEF (Scheme 1) [5]. FDCA production process primarily involves the dehydration of carbohydrates (C6 and C5 sugars) into alkoxymethyl furfurals (RMFs), being an intermediate mixture essentially containing methoxymethyl furfural (MMF), furfural (FA) and 5-hydroxymethyl furfural (HMF) in its composition. Besides leading to various furanics 
and other platform chemicals, the Acid Catalysed Dehydration (ACD) process essentially leads to the production of an unavoidable side stream residue called humins (Scheme 1).

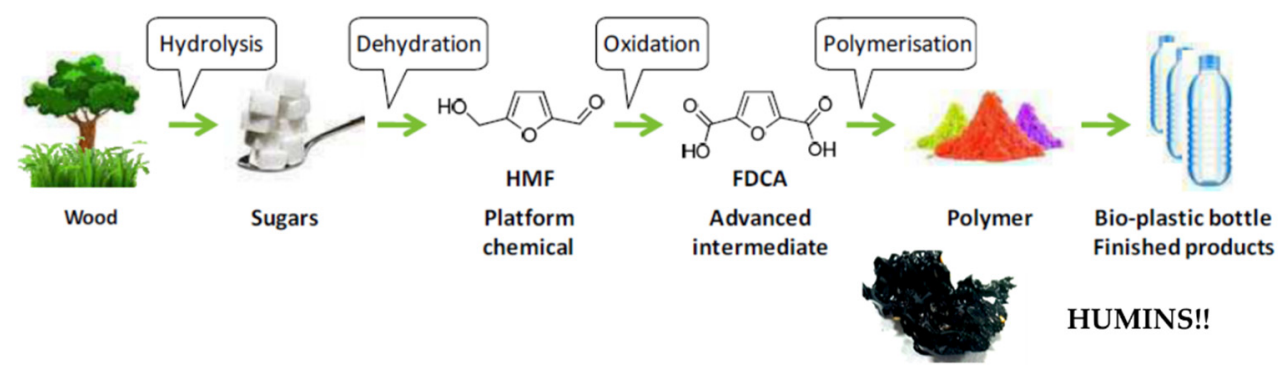

Scheme 1. Avantium's $Y X Y^{\circledR}$ process for PEF production generates two major side products: methyl levulinate and humins.

Humins are polyfuranic macromolecule mixtures with minor quantities of furanic derivatives retained in their structure [6]. The chemical structure of humins is highly complex and largely depends on the type of feedstock, operating conditions and the functional groups associated with them (Scheme 2) [7,8]. Despite its existence for many decades, humins have been mostly employed as residues in low-value applications such as combustion and gasification [9]. With the primary aim of valorising biorefinery side streams to improve the bio-based economy, innovative potential applications for humins as renewable raw materials have been identified mainly in catalysis, water purification, matrix of impregnation materials, $\mathrm{CO}_{2}$ sequestration and energy storage $[6,10,11]$, with very few reports to date on the valorisation of humins towards valuable chemicals production [12,13]. A recent report by Hallet et al. discloses the use of ionic liquids (ILs) for the production of humins in view of applications as valuable carbonaceous materials for antimony removal [14]. Additionally, we recently reported a plausible structure for humins obtained via several hydro/oxy-deconstruction strategies [15], following previous reports on structural characterisation of humins [8,14,16-18].
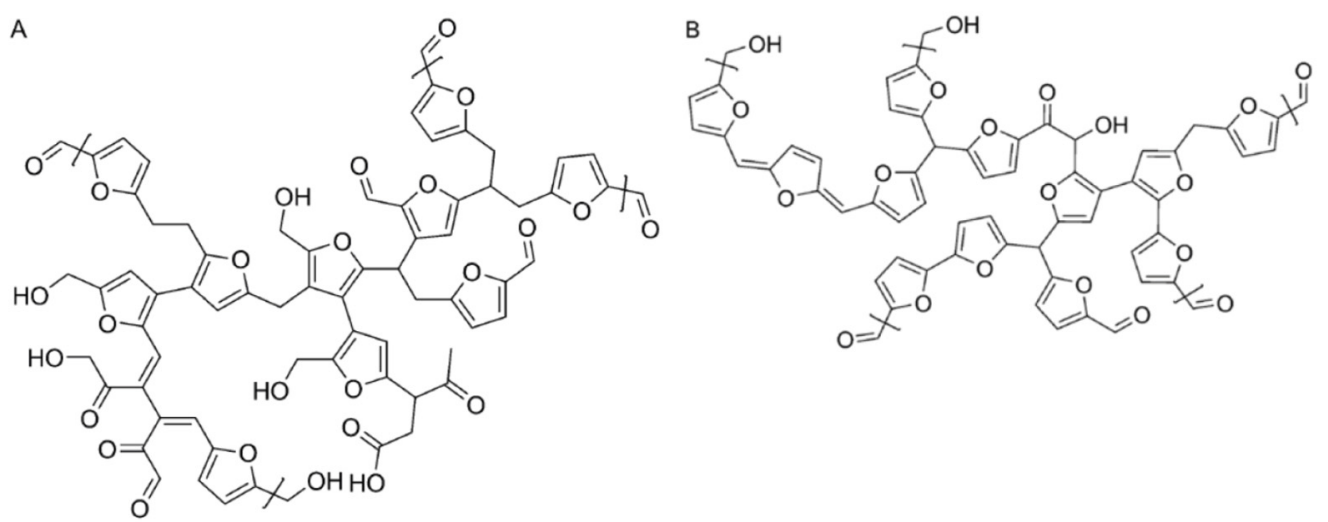

Scheme 2. Models representing humin fragments from (A) glucose-derived humins; (B) fructosederived humins. Reproduced from ref. [8].

New and alternative ways to synthesize APIs are largely needed in the EU due to their generally complex synthetic processes (typically 6-10 synthetic steps) and multiple rounds of quenching, separation and purification [19]. Neither innovator drug companies nor generic manufacturers have economic incentives to develop such novel, cost-saving alternative routes. Importantly, continuous flow technologies, combined with nano(bio)catalysis are highly advantageous for these purposes. Such benefits include better control of reaction conditions, which is especially advantageous in the case of highly reactive compounds such as those derived from biomass, the possibility of scaling up (of high interest and 
novelty in the waste-to-pharma concept) as well as less issues in catalyst separation (it stays after every run in the fixed bed reactor) and additional intermediate separation and purification steps. Lastly, continuous flow processes allow gas and/or product/byproduct removal during the reaction to not interfere in the proposed chemistries.

The identification of manufacturing routes that utilize the lowest-cost raw materials (e.g., humins) and most efficient tools available (e.g., continuous flow processes, photoredox catalysis) to make this a future reality, starting with the synthesis of two relevant APIs fully from humins (Ancarolol and Furosemide) will be reported in due course. A revolutionary and innovative approach for the valorisation of furanic-containing humins to valuable biofuranics with biological activities has been recently proposed by our group, driven by heterogeneous catalysis. All reactions are performed using low environmental impact technologies, including mechanochemistry and nano-(bio)catalysis as well as continuous flow processes in view of a future potential scaling-up (Figure 1, overall concept).

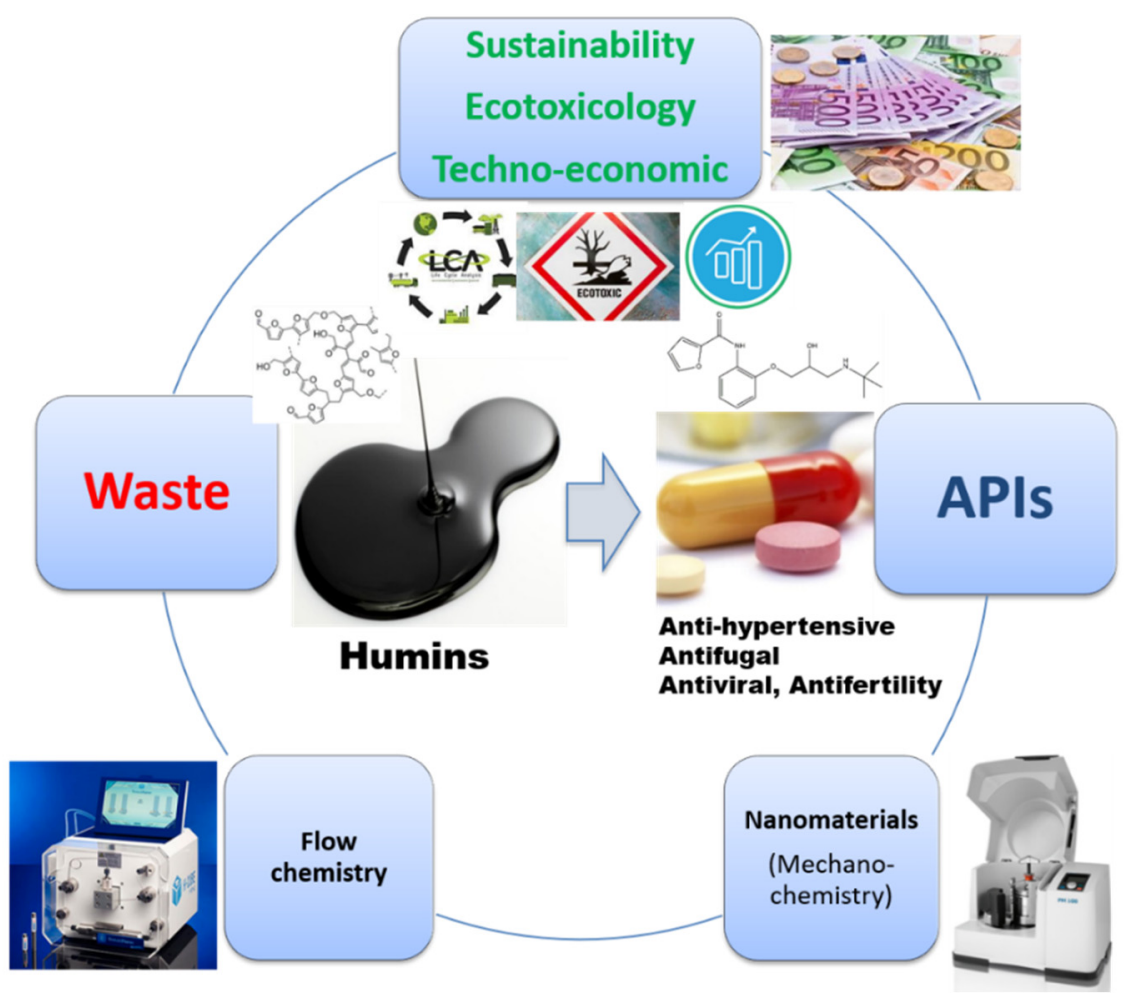

Figure 1. Project concept: from waste to the next generation of bioactive furanics under sustainable premises. The synthesis of APIs from biomass-derived waste has the potential to be conducted using green technologies, including mechanochemistry, photocatalysis and continuous flow processes (flow chemistry).

The first proposed relevant API synthesis deals with the preparation of atenolol analogues (antihypertensive drugs) from furanics derived from humins. Atenolol is an extensively prescribed API beta-blocker to treat high blood pressure [20] with a global market value of billion euros [21], being in the top 1\% of drugs prescribed for patients worldwide (over 30 million only in the USA in 2015 and expected to grow by $4.94 \%$ by 2023 [22]). Importantly, since 2017, Atenolol has been listed on the FDA Drug Shortages database, making it imperative to search for chemical analogues that can provide the required biological activity without major secondary effects.

Ancarolol derivatives (Scheme 3) have been selected as target molecules, being analogous beta-adrenergic blocking agents, due to their relevance and remarkably interesting compatible structure and biological activity featuring a furanic ring coupled to an orthoaminophenol derivative linked to a potential glycerol-derived tail [23]. Another potential 
synton (3-(tert-butylamino)-1,2-propanediol) that could be employed in the synthesis of the drug is a chemical intermediate utilized in the industrial chiral synthesis of related $\beta$ blockers-i.e., (S)-timolol-employed in the treatment of various cardiovascular disorders such as hypertension, angina pectoris and cardiac arrhythmia [24].<smiles>OCC(O)CO</smiles>

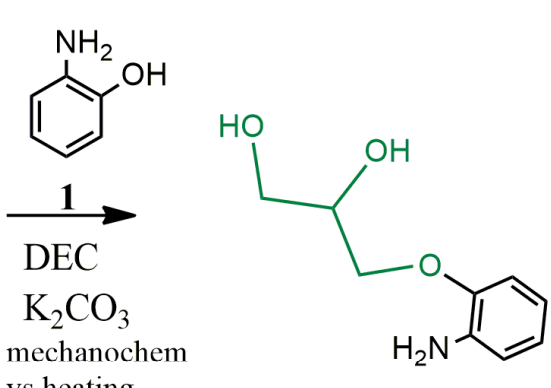<smiles>[R]c1ccc(C=O)o1</smiles><smiles>O=C(Nc1ccccc1OCC(O)CO)c1ccc(P)o1</smiles><smiles>[R]c1ccc(C(=O)Nc2ccccc2OCC(O)CNC(C)(C)C)o1</smiles>

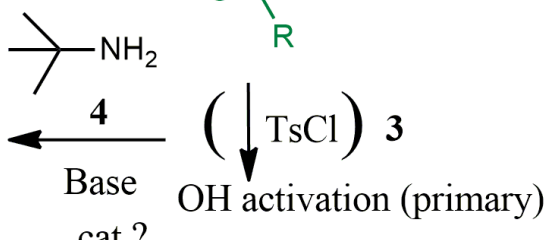

Ancarolol $(\mathrm{R}=\mathrm{H})$

Scheme 3. Proposed Ancarolol analogue syntheses from renewable feedstocks: humins and glycerol. DEC: Diethyl carbonate; $\mathrm{K}_{2} \mathrm{CO}_{3}$ : potassium carbonate. Step 3 involves the addition of Tosyl chloride (TsCl) as an activating group for primary $\mathrm{OH}$ activation from the glycerol moiety.

The proposed synthetic process involves four steps in principle, including the activation of the primary $\mathrm{OH}$ group for the final reaction, as illustrated in Scheme 3. The first step (1) involves a simple and previously reported one-pot synthesis of aryloxypropanediols using glycerol as starting material with various phenols including 2-methoxyphenol $(99 \%$ conversion, $8 \mathrm{~h}, 110^{\circ} \mathrm{C}$ ) [25] however unreported for 2-aminophenol. Interestingly, such reaction generated an additional unexpected benzoxazine API-type product from the cyclisation of 2-aminophenol and glycerol [(3,4-dihydro-2H-benzo[b][1,4]-oxazin-3-yl)methanol, Scheme 4) with promising biological activities [26]. The intramolecular cyclisation reaction may involve $\mathrm{OH}$ activation taking place under mechanochemical conditions and the presence of potassium carbonate.

Benzoxazines are core motifs in relevant APIs including apararenone [27], elbasvir [28], and etifoxine [29].

Preliminary results indicate that furfural in the second step (2) can also be successfully coupled with aromatic amines (aniline, benzylamine as well as the obtained 3-(2aminophenoxy)propane-1,2-diol in step 1) under pulsed laser/LED irradiation using plasmonic systems (e.g., $\mathrm{Au}$ and $\mathrm{Ag}$-based $\mathrm{TiO}_{2}$ catalysts) [30] via most plausible oxidative amidation (oxidation of the aldehyde group in furfural to carboxylic acid and addition of amine to form the amide) as previously reported by our group [31]. Subsequent steps can lead to a final ancarolol derivative in which more than half of the molecule is derived from renewable feedstocks (glycerol and humins). Preliminary calculations pointed to an atom economy of the whole synthetic process over 70\%, with an E-factor of 7 [30], far from classical values (25-100) from the pharmaceuticals industry.

The other example for API synthesis is Furosemide. Furosemide is an extensively prescribed API with interesting biological activities in the treatment of fluid build-up (loop diuretic) due to heart failure, liver scarring, or kidney diseases [32], being in the World Health Organisation's List of Essential Medicines as most effective and safest required in a health system [33]. The structure of Furosemide (Scheme 5) can be synthesized in three 
steps in a relatively simple way (also under continuous flow conditions), starting from furfural/furanics.

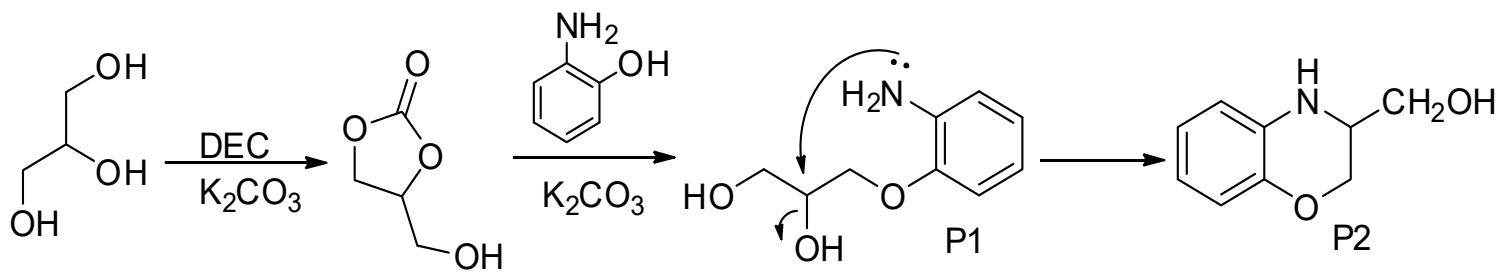

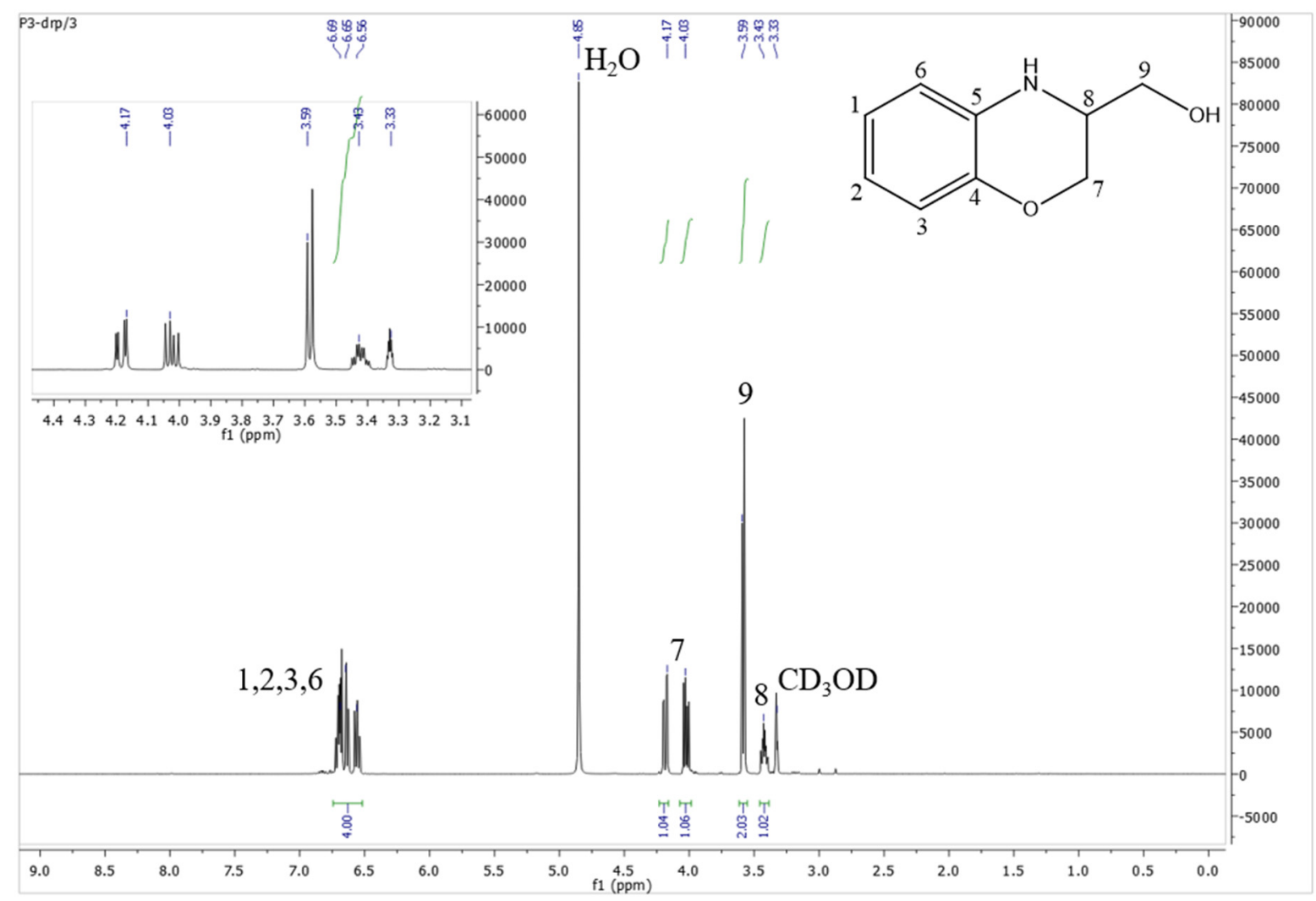

Scheme 4. Plausible reaction mechanism for 3,4-dihydro-2H-benzo[b][1,4]-oxazin-3-yl)methanol formation from glycerol and 2-aminophenol (top). ${ }^{1} \mathrm{H}-\mathrm{NMR}$ spectrum of purified benzoxazine product (bottom). DEC: Diethyl carbonate; $\mathrm{K}_{2} \mathrm{CO}_{3}$ : potassium carbonate.<smiles>[R]c1ccc(C=O)o1</smiles>

$$
\begin{aligned}
& \stackrel{\mathrm{Rh} / \mathrm{TiO}_{2}}{\longrightarrow} \\
& 100^{\circ} \mathrm{C} \\
& \mathrm{NH}_{3}, \mathrm{H}_{2} \\
& \text { Batch vs flow }
\end{aligned}
$$

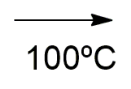<smiles>O=C(O)c1ccc(Cl)cc1Cl</smiles><smiles>NS(=O)(=O)c1cc(C(=O)O)c(Cl)cc1Cl</smiles><smiles>[R]c1ccc(CNc2cc(Cl)c(S(N)(=O)=O)cc2C(=O)O)o1</smiles>

Furosemide $(\mathrm{R}=\mathrm{H})$

Scheme 5. Proposed synthesis of Furosemide from furanics. Reactions performed in batch could be translated into more scalable continuous flow approaches. 
The proposed synthesis involves the reductive amination of furanics (including furfural and HMF) using a simple and mild reductive amination catalysed by $\mathrm{Rh} / \mathrm{TiO}_{2}$ materials $\left(94 \%\right.$ yield from furfural to furfurylamine using $0.5 \% \mathrm{Rh} / \mathrm{TiO}_{2}, 2 \mathrm{~h}$ reaction, $100{ }^{\circ} \mathrm{C}$ ), similar to those reported to be most effective in such reaction [34]. Results are currently under translation into the continuous flow using H-Cube reactors [35,36]. Additionally, 2,4-dichlorobenzoic acid has been reacted in two steps (first $\mathrm{SO}_{3} \mathrm{HCl}$, then ammonia) to form the chloro-substituted sulfamoylbenzoic acid that will eventually react with furfuryl amine to yield Furosemide (for furfural) and derivatives.

We hope the present contribution can stimulate scientists to further develop the wasteto-pharma concept and look forward to witnessing further developments on the topic in the years to come, all for a more sustainable future for the betterment of humankind.

Author Contributions: R.L., Z.A.A., A.M.B. and L.V. contributed to write and revise the manuscript. R.L. conceptualized the work, led the project and supervised the preliminary results reported here. All authors have read and agreed to the published version of the manuscript.

Funding: This work was supported by the Distinguished Scientist Fellowship Program (DSFP) at King Saud University, Riyadh, Saudi Arabia. This publication has been supported by RUDN University Strategic Academic Leadership Program (L. Voskressensky). R.L. also gratefully acknowledges funding from Consejeria de Transformación Económica, Industria, Conocimiento y Universidades, Secretaría General de Universidades, Investigación y Tecnología, Junta de Andalucia for funding under project P18-RT-4576 on the waste-to-pharma concept.

Institutional Review Board Statement: Not applicable.

Informed Consent Statement: Not applicable.

Data Availability Statement: Not applicable.

Conflicts of Interest: The authors declare no conflict of interest.

\section{References}

1. Available online: https:/ /ec.europa.eu/eurostat/statistics-explained/index.php?title=Waste_statistics (accessed on 28 October 2021).

2. Tadesse, H.; Luque, R. Advances on biomass pretreatment using ionic liquids: An overview. Energy Environ. Sci. 2011, 4, 3913-3929. [CrossRef]

3. Ed de Jong, G.-J.G. Furanics: A Novel Diesel Fuel with Superior Characteristics. In Proceedings of the SAE 2009 Powertrains Fuels and Lubricants Meeting, San Antonio, TX, USA, 2 November 2009.

4. Bozell, J.J.; Petersen, G.R. Technology development for the production of biobased products from biorefinery carbohydrates-The US Department of Energy's “Top 10" revisited. Green Chem. 2010, 12, 539-554. [CrossRef]

5. Available online: https://www.avantium.com/technologies/yxy/ (accessed on 28 October 2021).

6. Filiciotto, L.; Balu, A.M.; Van Der Waal, J.C.; Luque, R. Catalytic insights into the production of biomass-derived side products methyl levulinate, furfural and humins. Catal. Today 2018, 302, 2-15. [CrossRef]

7. Wang, S.; Lin, H.; Zhao, Y.; Chen, J.; Zhou, J. Structural characterization and pyrolysis behavior of humin byproducts from the acid-catalyzed conversion of C6 and C5 carbohydrates. J. Anal. Appl. Pyrolysis 2016, 118, 259-266. [CrossRef]

8. Van Zandvoort, I.; Wang, Y.; Rasrendra, C.B.; Van Eck, E.R.H.; Bruijnincx, P.C.A.; Heeres, H.J.; Weckhuysen, B.M. Formation, Molecular Structure, and Morphology of Humins in Biomass Conversion: Influence of Feedstock and Processing Conditions. ChemSusChem 2013, 6, 1745-1758. [CrossRef] [PubMed]

9. Hoang, T.M.C.; Lefferts, L.; Seshan, K. Valorization of Humin-Based Byproducts from Biomass Processing-A Route to Sustainable Hydrogen. ChemSusChem 2013, 6, 1651-1658. [CrossRef]

10. Mija, A.; van der Waal, J.C.; Pin, J.-M.; Guigo, N.; de Jong, E. Humins as promising material for producing sustainable carbohydrate-derived building materials. Constr. Build. Mater. 2017, 139, 594-601. [CrossRef]

11. Hu, B.; Wang, K.; Wu, L.; Yu, S.-M.; Antonietti, M.; Titirici, M.-M. Engineering carbon materials from the hydrothermal carbonization process of biomass. Adv. Mater. 2010, 22, 813-828. [CrossRef] [PubMed]

12. Pfab, E.; Filiciotto, L.; Romero, A.A.; Luque, R. Valorisation of humins-extracted 5-methoxyfurfural: Toward high added value furanics via continuous Flow catalytic hydrogenation. Ind. Eng. Chem. Res. 2019, 58, 16065-16070. [CrossRef]

13. Ouyang, W.; Yepez, A.; Romero, A.A.; Luque, R. Towards industrial furfural conversion: Selectivity and stability of palladium and platinum catalysts under continuous flow regime. Catal. Today 2018, 308, 32-37. [CrossRef]

14. Al Ghatta, A.; Zhou, X.; Casarano, G.; Wilton-Ely, J.D.E.T.; Hallett, J.P. Characterization and Valorization of Humins Produced by HMF Degradation in Ionic Liquids: A Valuable Carbonaceous Material for Antimony Removal. ACS Sustain. Chem. Eng. 2021, 9 , 2212-2223. [CrossRef] 
15. Filiciotto, L.; Balu, A.M.; Romero, A.A.; Angelici, C.; van der Waal, J.C.; Luque, R. Reconstruction of humins formation mechanism from decomposition products: A GC-MS study based on catalytic continuous flow depolymerizations. Mol. Catal. 2019, 479, 110564. [CrossRef]

16. Hoang, T.M.C.; van Eck, E.R.H.; Bula, W.P.; Gardeniers, J.G.E.; Lefferts, L.; Seshan, K. Humin Based By-Products from Biomass Processing as a Potential Carbonaceous Source for Synthesis Gas Production. Green Chem. 2015, 17, 959-972. [CrossRef]

17. Patil, S.K.R.; Lund, C.R.F. Formation and Growth of Humins via Aldol Addition and Condensation during Acid-Catalyzed Conversion of 5-Hydroxymethylfurfural. Energy Fuels 2011, 25, 4745-4755. [CrossRef]

18. Cheng, Z.; Vlachos, D.G.; Everhart, J.L.; Tsilomelekis, G.; Nikolakis, V.; Saha, B. Structural Analysis of Humins Formed in the Brønsted Acid Catalyzed Dehydration of Fructose. Green Chem. 2018, 20, 997-1006. [CrossRef]

19. Gutmann, B.; Cantillo, D.; Kappe, C.O. Continuous-Flow Technology-A Tool for the Safe Manufacturing of Active Pharmaceutical Ingredients. Angew. Chem. Int. Ed. 2015, 54, 6688-6728. [CrossRef]

20. Available online: https:/ / www.drugbank.ca/drugs/DB00335 (accessed on 28 October 2021).

21. Available online: https://www.theatlantic.com/health/archive/2017/02/when-evidence-says-no-but-doctors-say-yes/517368/ (accessed on 28 October 2021).

22. Available online: https://marketresearchandanalysisweb.wordpress.com/2018/10/04/global-atenolol-market-become-domi nant-at-cagr-of-4-94-by-2023/ (accessed on 28 October 2021).

23. Banerjee, R.; Kumar, H.K.S.; Banerjee, M. Medicinal significance of furan derivatives: A Review. Int. J. Rev. Life Sci. 2012, 2, 7-16.

24. Toussaint, B.; Streel, B.; Ceccato, A.; Hubert, P.; Crommen, J. Determination of the enantiomers of 3-tert-butylamino-1,2propanediol by high-performance liquid chromatography using mass spectrometric detection. J. Chromatogr. A 2000, 896, $201-207$. [CrossRef]

25. Truscello, A.M.; Gambarotti, C.; Lauria, M.; Auricchio, S.; Leonardi, G.; Shisodia, S.U.; Citterio, A. One-pot synthesis of aryloxypropanediols from glycerol: Towards valuable chemicals from renewable sources. Green Chem. 2012, 15, 625-628. [CrossRef]

26. Luque, R. Glycerol valorisation: Towards benzoxazine derivatives via milling/microwave sequential strategy. Unpublished results. 2021.

27. Available online: https://en.wikipedia.org/wiki/Apararenone (accessed on 28 October 2021).

28. Available online: https:/ / en.wikipedia.org/wiki/Elbasvir (accessed on 28 October 2021).

29. Available online: https:/ / en.wikipedia.org/wiki/Etifoxine (accessed on 28 October 2021).

30. Luque, R. Plasmonic-Mediated Oxidative Amidation of Furfural with Aromatic Amines. Unpublished results. 2021.

31. Pineda, A.; Gomez, L.; Balu, A.M.; Sebastian, V.; Ojeda, M.; Arruebo, M.; Romero, A.A.; Santamaria, J.; Luque, R. Laser-driven heterogeneous catalysis: Efficient amide formation catalysed by $\mathrm{Au} / \mathrm{SiO}_{2}$ systems. Green Chem. 2013, 15, 2043-2049. [CrossRef]

32. Available online: https://www.drugs.com/monograph/furosemide.html (accessed on 28 October 2021).

33. Available online: http://www.who.int/medicines/publications/essentialmedicines/EML_2015_FINAL_amended_NOV2015 .pdf?ua=1 (accessed on 28 October 2021).

34. Chatterjee, M.; Ishizaka, T.; Kawanami, H. Reductive amination of furfural to furfurylamine using aqueous ammonia solution and molecular hydrogen: An environmentally friendly approach. Green Chem. 2015, 18, 487-496. [CrossRef]

35. Available online: https://thalesnano.com/products-and-services/h-cube-pro/ (accessed on 28 October 2021).

36. Luque, R. Reductive Amination of Furfural for Furfurylamine Production: A Comparison between Batch vs. Flow Chemistry Reactions. Unpublished Results. 2021. 